An index of business activity must therefore cast its net far wider than industrial production. It must take account not only of the rate at which goods are produced but also of the rates at which they are distributed, transported and sold.

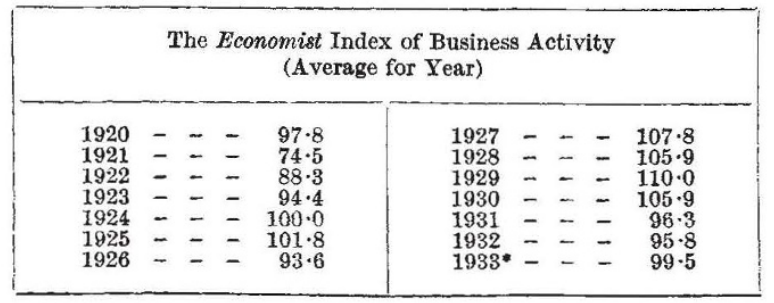

* Provisional ; 11 months average.

The Economist "Index of Business Activity" is published monthly and is based on a weighted series of indices relating to employment, the iron and steel and cotton industries, imports of raw materials and non-ferrous metals, exports of manufactures, railway traffic, shipping movements, consumption of coal and electricity, postal receipts, bank clearings, building activity and the registration of motor vehicles.

\section{History of Mathematical Time}

T WO articles under the above title by $\mathrm{G}$. Windred have been published in Isis, 19 and 20, in 1933 In the first the author traces the development of the concept of mathematical time from its origins with Napier, Barrow and Leibniz up to the theory of pure time of Sir William Rowan Hamilton. Within the short space of some thirty pages, the author gives an excellent account of Barrow's theory of mathematical time, which formed the basis of the time concept in Newtonian mechanics for more than two centuries. He traces the progress of the concept in the writings of Newton, Maclaurin and Kant, and concludes with a brief account of Hamilton's views on algebra as the science of pure time.

The second article is devoted to the history of time in the mathematical physics of the twentieth century. The author gives a brief account of the fundamental papers of H. A. Lorentz, Poincaré, Einstein and Minkowski concerning 'local' time, simultaneity of events and the synthesis of space and time into one whole in the special theory of relativity. He passes on to a relatively full account of Robb's theory of 'conical order' and concludes with brief references to the later work of Einstein, the system of time due to A. N. Whitehead, the views of Eddington, Vasiliev and Synge, and recent ideas on the atomic structure of time, due principally to Robert Lévy and Pokrowski. Here one misses any reference to the writings of $\mathrm{H}$. Reichenbach, more particularly his "Philosophie der Raum-Zeit-Lehre", 1928, where a good deal of space is devoted to a discussion of the nature of time. Apart from this omission this part of the essay gives a clear and relatively full account of the changes brought about by the advent of the theory of relativity in our ideas of time. The last section of the essay gives a summary of the applications of the theory of time to mechanics and mathematical physics and of its implications for philosophy and psychology.
The essay can be highly recommended to anyone, whother mathematician, philosopher or physicist, who. needs a brief summary of the history of the concept of time from its origin to its latest develop. ments. It is well supplied with references and so can serve as a guide to anyone desirous of studying the question more completely than is possible in so short an essay.

\section{University and Educational Intelligence}

CAmbridge.-The Buildings Syndicate recommends that the vacant site between the Museum of Archæology and Ethnology and the Botany School be assigned for an extension of the Museum, provided that this assignment be reconsidered if no permanent building is erected on the site within ten years.

The Council of the Senate recommends that a pension of $£ 430$ a year be granted to Prof. J. T. Wilson on his retirement from the professorship of anatomy.

The Faculty Board of Medicine recommends the establishment of a Marmaduke Shield scholarship in human anatomy of the value of $£ 100$ a year.

OXForD.--In Congregation on March 3, the degree of D.Sc. was conferred on Charles K. Meek (Brasenose College), Government anthropologist in Nigeria, and author of three important works: "A Sudanese Kingdom" (1931); "Tribal Studies in Northern Nigeria" (1931) ; "The Northern Tribes of Nigeria" (1925).

ADult education is being exploited in the United States on a vast scale by the Federal Emergency Relief Administration as a means of providing work for unemployed teachers (including many unemployed persons who are potential though not professed teachers) and at the same time raising the standard of employability of the general mass of unemployed. Any person now on relief or urgently in need of a job, who is a college graduate or able to offer other proof of intellectual ability, is to be given an opportunity of employment as teacher. The scheme has six divisions, of which two are outside the field of adult education: teaching of 'illiterates', which is construed to mean education of adults up to sixth-grade level, general adult education, trade schools, training of physically disabled persons, reopening of rural schools closed for want of funds to pay teachers, and nursery schools in mining camps, mill villages and other places where children, especially children of the unemployed, are not being adequately cared for. It is anticipated that where the local organisation is slow in developing a general adult educational project, a competent unemployed seientifie worker will work up a class for himself to teach, whereupon he will be enrolled as a paid instructor. The rates of payment have been revised, the former limit of 15 dollars a week having been withdrawn. The trade schools will provide employment for many engineers thrown out of work by industrial depression and the nursery schools will absorb some of the unemployed women trained in child psychology or kindergarten. School and Society of December 2 has an authoritative leading article describing the scheme. 